\title{
Two Unusual Cases of the Posterior Cranial Fossa Blood Supply
}

\author{
Daxa M. Patel ${ }^{1}$, Martin M. Mortazavi ${ }^{2}$, R. Shane Tubbs ${ }^{3}$, Joel Cure ${ }^{4}$, Winfield S. Fisher ${ }^{5}$ \\ 1. Neurosurgery, University of Alabama at Birmingham 2. California Institute of Neuroscience, Los \\ Robles Hospital and Medical Center 3. Neurosurgery, Seattle Science Foundation 4. Radiology, \\ University of Alabama at Birmingham 5. Neurological Surgery, University of Alabama at Birmingham
}

$\square$ Corresponding author: Daxa M. Patel,dmp278@gmail.com

Disclosures can be found in Additional Information at the end of the article

\section{Abstract}

Variations of the posterior fossa blood supply are relatively uncommon but should be borne in mind by the clinician.

We present two unusual cases of posterior cranial fossa blood supply and review the literature regarding such abnormalities.

Both cases demonstrated a lack of the vertebrobasilar system to varying degrees.

Such arterial variations as present herein should be known to the clinician dealing with the treatment of patients with pathology of the posterior cranial fossa.

Categories: Neurosurgery

Keywords: vertebral artery atresia, atresia, posterior fossa circulation, hypoplasia, collateral circulation

\section{Introduction}

The arterial supply to the brain is normally provided through the internal carotid and vertebral arteries [1]. The carotid and vertebrobasilar systems are normally interconnected through the posterior communicating arteries and unusually through the persistent fetal circulation [2]. There is also an extracranial collateral circulation through the external carotid arteries, especially through the anastomosis with the ethmoidal branches of the ophthalmic artery, as well as dural and meningeal arteries [3]. The extent of the non-fetal collaterals increases with age and with some pathologic diseases, such as Moya Moya [4]. The primary connections

Received 04/18/2014 Review began 04/19/2014 Review ended 04/29/2014 Published 04/30/2014

C) Copyright 2014

Patel et al. This is an open access article distributed under the terms of the Creative Commons Attribution License CC-BY 3.0., which permits unrestricted use, distribution, and reproduction in any medium, provided the original author and source are credited. between the internal carotid and vertebrobasilar circulations are the posterior communicating arteries [5]. One common variant is a dominant ipsilateral posterior communicating artery and a contralateral fetal posterior communicating artery [6]. Vertebral artery atresia is a rare congenital anomaly [2, 7-10] and vertebral artery agenesis is even more rare [11].

\section{Case Presentation}

\section{Case 1}

A 52-year-old right-handed white female presented to the neurosurgery clinic in November 2001 with symptoms of dizziness and neck pain for several months that had progressed. Her past medical history was significant for benign positional vertigo, hypertension, and 


\section{Cureus}

hyperlipidemia. Her physical exam was negative for neurological deficits. MRI and MRA indicated a right internal carotid artery stenosis, and an endarterectomy was performed to treat this. MRA also demonstrated a severely hypoplastic posterior circulation with bilateral atresia of the vertebral arteries and termination of these vessels as the posterior inferior cerebellar arteries. The patient was subsequently followed on an annual basis with imaging. At follow-up, she remained asymptomatic without any new complaints or neurologic deficits. Threedimensional (3D) angiography confirmed bilateral atresia of the vertebral arteries and lack of a basilar artery (Figures 1,2). Bilateral fetal posterior cerebral arteries provided posterior circulation with the vertebral arteries terminating into left and right PICA with some minimal anterior vertebrobasilar system extending cephalad to join with the right posterior communicating arteries.

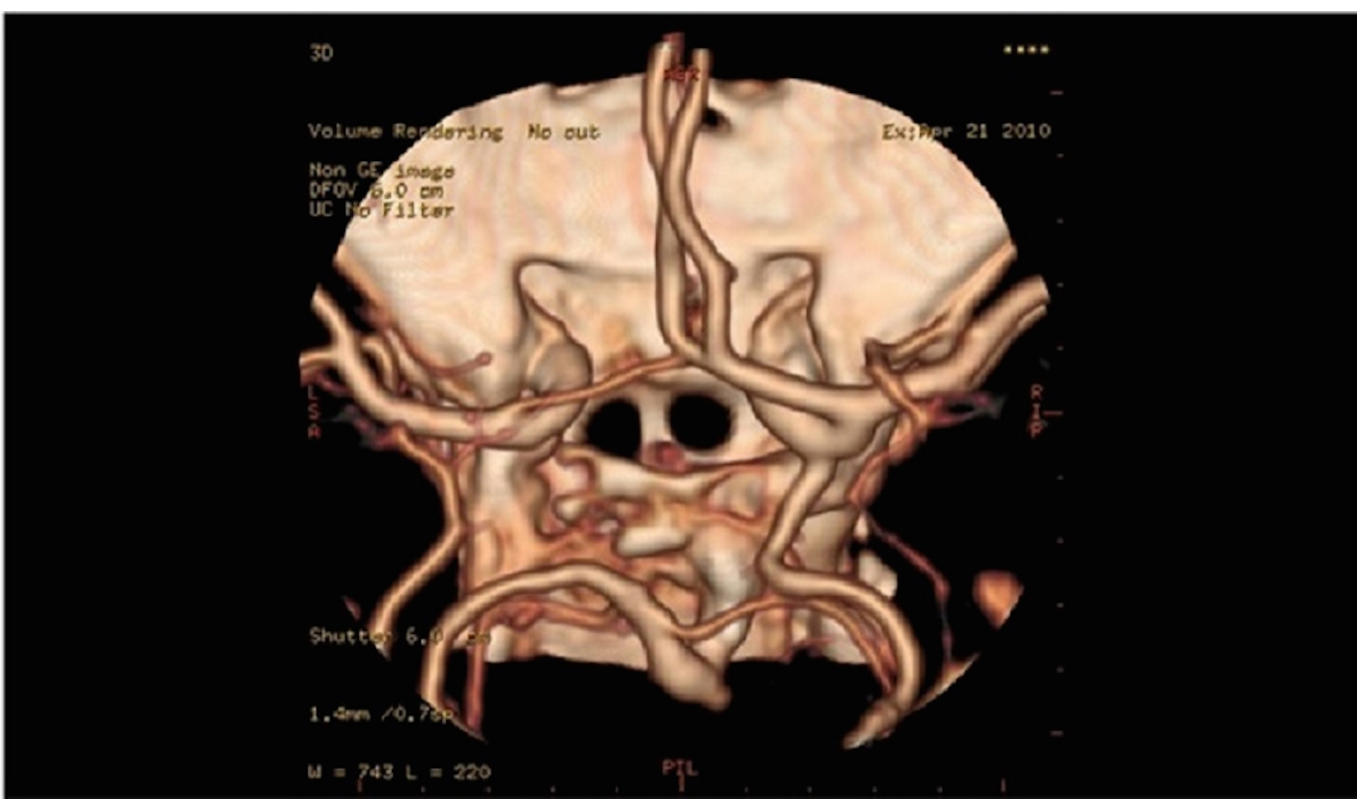

\section{FIGURE 1: Imaging of Case 1. CTA}

It demonstrates a severely hypoplastic posterior circulation with bilateral atresia of the vertebral arteries and termination of these vessels as the posterior inferior cerebellar arteries.

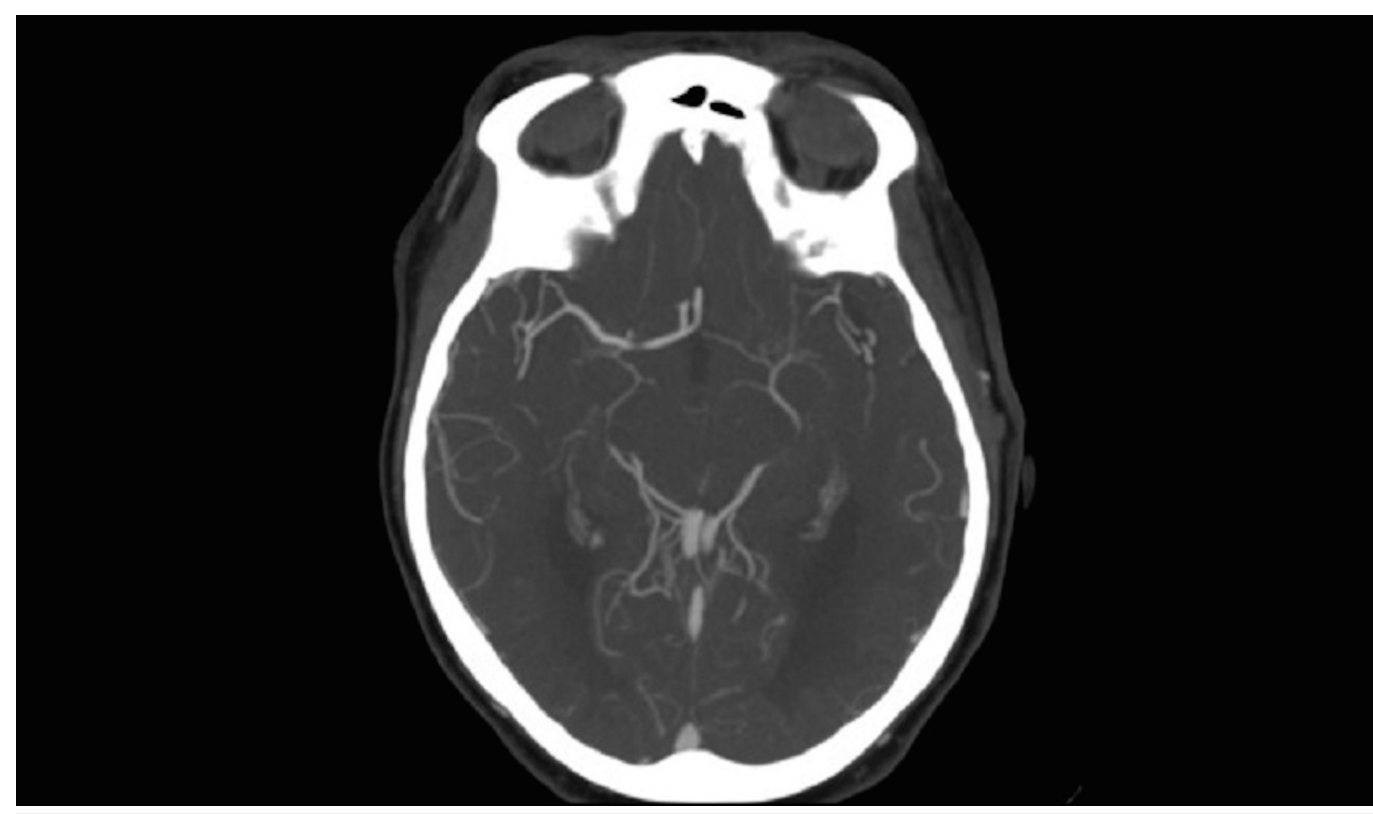


It demonstrates bilateral atresia of the vertebral arteries. Bilateral fetal posterior cerebral arteries provided posterior circulation with some minimal anterior vertebrobasilar system extending cephalad to join with the right posterior communicating arteries.

\section{Case 2}

A 69-year-old right-handed white female presented with some short-term memory problems and was found to have a right cavernous ICA aneurysm. Her past medical history was significant for hypertension, hyperlipidemia, peripheral vascular disease, urinary incontinence, and stents placed in her left lower extremity arteries. She has no family history of aneurysms and was a long-term smoker. Her physical exam was normal. CT angiogram of the head and neck demonstrated a petrous carotid artery aneurysm $(3 \times 2 \mathrm{~mm})$ and a persistent right trigeminal artery. The posterior circulation flow was mainly supplied via a fetal posterior cerebral artery on the right side. The 3D arteriogram confirms bilateral atresia of the vertebral arteries and lack of a basilar artery (Figures 3, 4). There was minimal anterior vertebrobasilar system extending cephalad to join with the right posterior communicating artery. At last follow up, her aneurysm was stable in size. 


\section{Cureus}

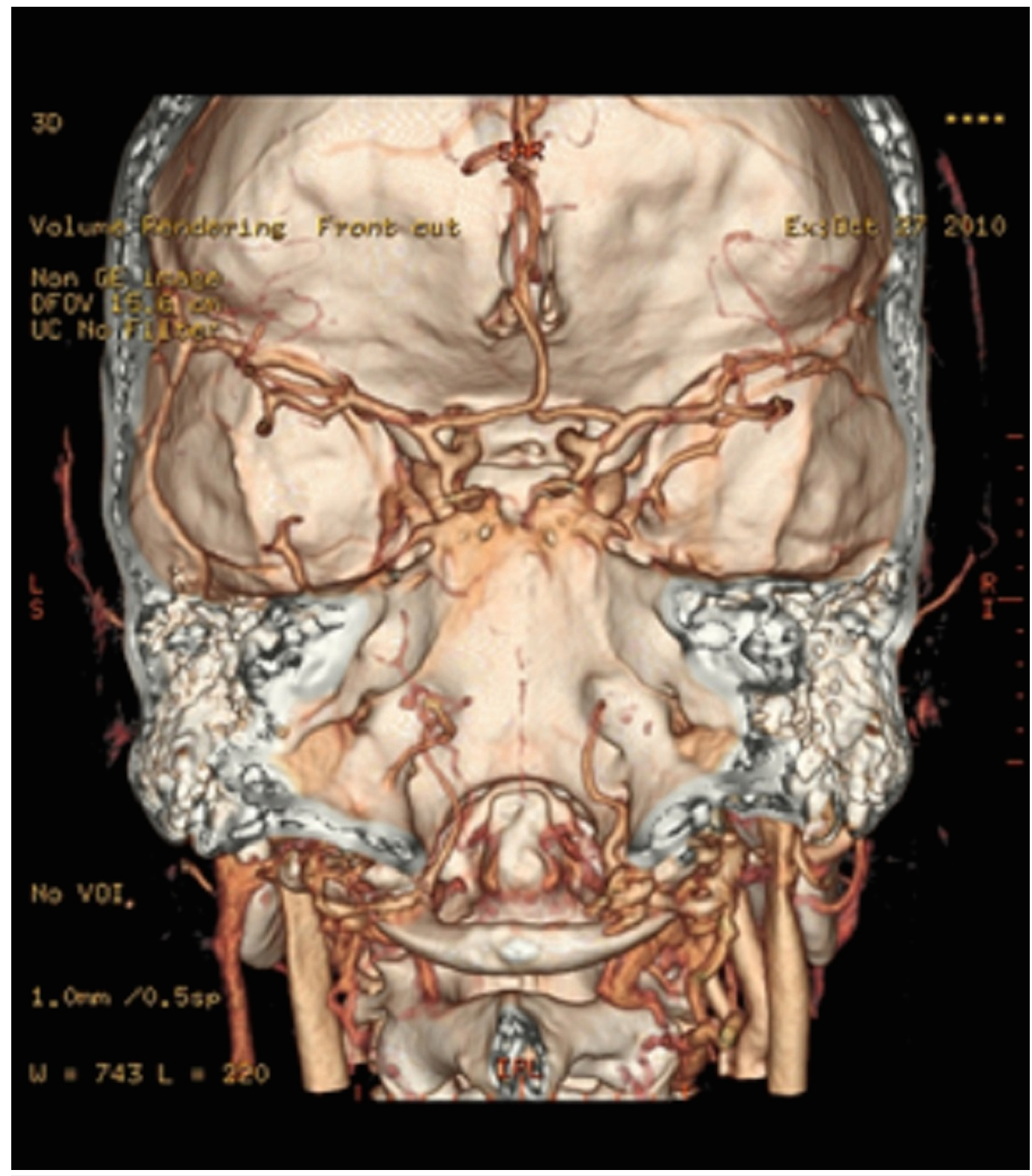

FIGURE 3: Imaging of Case 2. CTA

It demonstrates posterior circulation flow mainly supplied via a fetal posterior cerebral artery on the right side. The 3-dimensional arteriogram confirms bilateral atresia of the vertebral arteries and lack of a basilar artery. 


\section{Cureus}

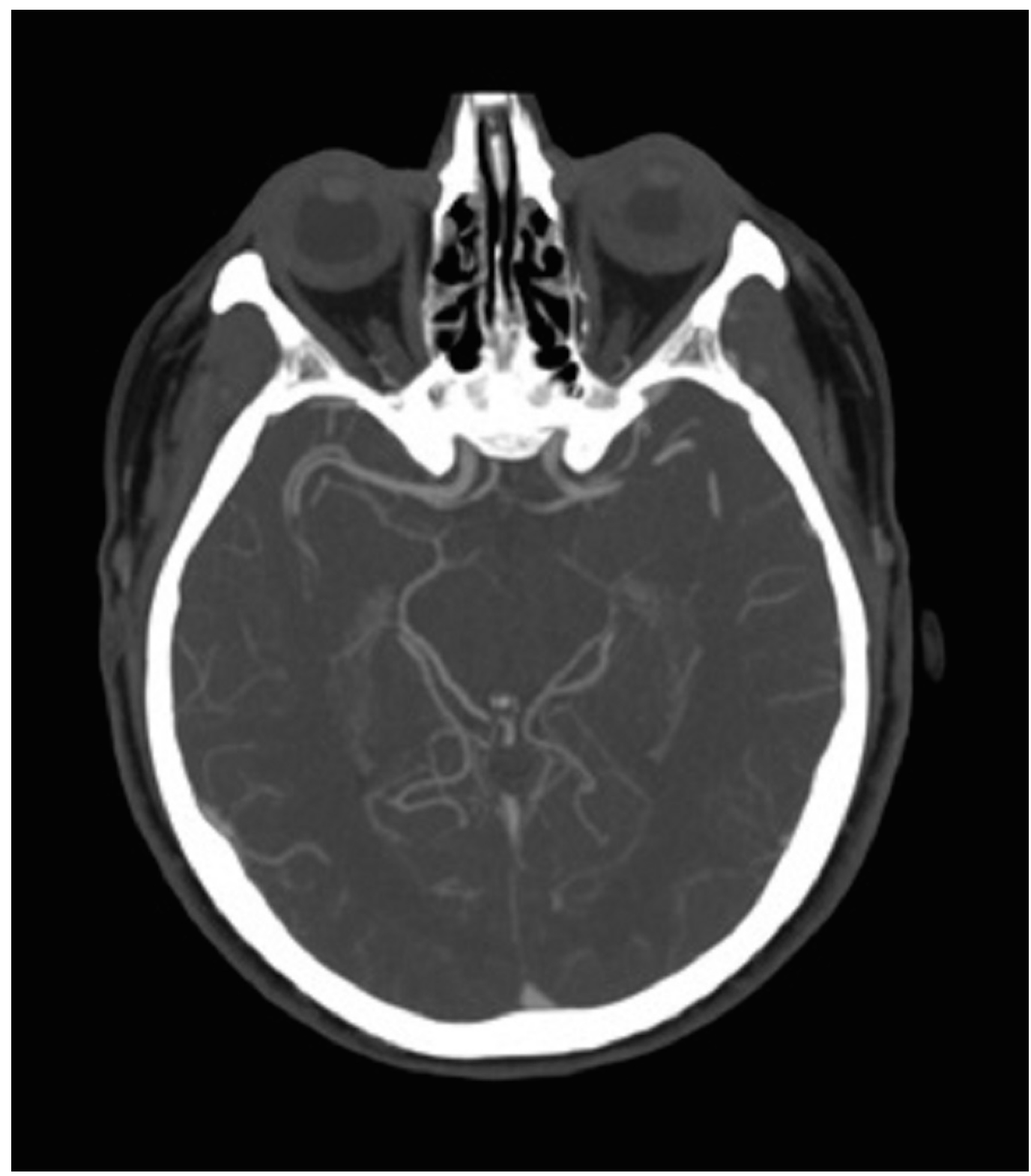

\section{FIGURE 4: Imaging of Case 2. MRA}

It demonstrates bilateral atresia of the vertebral arteries. There was minimal anterior vertebrobasilar system extending cephalad to join with the right posterior communicating artery.

\section{Discussion}

Early development of the basilar artery occurs via a longitudinal and axial axis. Longitudinal fusion occurs in the midline between the ventral arteries, similar to that seen along the spinal cord. Axial fusion forms the distal basilar artery and occurs from the caudal division of the internal carotid artery. The vertebral artery develops as a series of longitudinal anastomoses between the sixth intersegmental and proatlantal arteries [12]. Absence of parts of or the entire basilar artery may be compensated for by a persistent trigeminal artery, which usually involutes by the 7-12 mm stage [13]. This scenario was observed in one of our cases. With agenesis or atresia of the vertebral artery, cerebral perfusion is maintained by collateral flow from the anterior circulation through the posterior communicating arteries or via a persistent fetal circulation [14]. Dural branches may also play a role in supplementing the posterior circulation $[5,9,15]$. Although rare reports of vertebral "rete mirable" have been published, to our 
knowledge, bilateral atresia of the vertebral arteries has not been reported [16-17].

Some studies have found that hypoplasia of the vertebral artery system puts individuals at risk for stroke of the posterior circulation [18-19]. Such collateral circulations can impede endovascular procedures [20]. Hoh, et al. [13] reported an adult male with axial nonfusion and a child with longitudinal nonfusion of the basilar artery. Our Case 2 is comparable to Hoh, et al.'s [13] adult case. Burger, et al. [12] reported basilar artery agenesis with each vertebral artery terminating as a posterior inferior cerebellar artery. In the absence of basilar artery agenesis, some have found a vertebral artery terminating as a posterior inferior cerebellar artery in up to $13 \%$ of studied patients [11]. This case received collateral blood supply from a persistent left trigeminal artery.

\section{Conclusions}

Although apparently very rare, cases such as presented herein should be borne in mind by the clinician who interprets imaging or the neurosurgeon or interventionalist who treat patients with intracranial pathology.

\section{Additional Information \\ Disclosures}

Human subjects: All authors have confirmed that this study did not involve human participants or tissue. Conflicts of interest: In compliance with the ICMJE uniform disclosure form, all authors declare the following: Payment/services info: All authors have declared that no financial support was received from any organization for the submitted work. Financial relationships: All authors have declared that they have no financial relationships at present or within the previous three years with any organizations that might have an interest in the submitted work. Other relationships: All authors have declared that there are no other relationships or activities that could appear to have influenced the submitted work.

\section{References}

1. Chen YY, Chao AC, Hsu HY, Chung CP, Hu HH: Vertebral artery hypoplasia is associated with a decrease in net vertebral flow volume. Ultrasound Med Biol. 2010, 36:38-43.

2. Sreedhar M, Reddy K, Agrawal MK: Case report: Bilateral agenesis of internal carotid arteries associated with aneurysmally dilated plexus of vessels in the posterior fossa. Neuroradiology. 2007, 17:159-161.

3. Courson B, Laffont J, Giordano C: Extra-cranial vertebro-occipital anastomosis (in French) . Bull Soc Med Afr Noire Lang Fr. 1966, 11:378-81.

4. Burke GM, Burke AM, Sherma AK, Hurley MC, Batjer HH, Bendok BR: Moyamoya disease: a summary. Neurosurg Focus. 2009, 26:E11. 10.3171/2009.1.FOCUS08310

5. Salamon G, Huang YP: Radiologic Anatomy of the Brain. Springer-Verlag, Berlin; 1976.

6. Raamt AF, Mali W, Laar JV, Graaf Y: The fetal variant of the circle of Willis and its influence on the cerebral collateral circulation. Cerebrovasc Dis. 2006, 22:217-224.

7. Afifi AK, Godersky JC, Menezes A, Smoker WR, Bell WE, Jacoby CG: Cerebral hemiatrophy, hypoplasia of internal carotid artery, and intracranial aneurysm: A rare association occurring in an infant. Arch Neurol. 1987, 44:232-235.

8. Chen CJ, Chen ST, Hsieh FY, Wang LJ, Wong YC: Hypoplasia of the internal carotid artery with intercavernous anastomosis. Neuroradiology. 1998, 40:252-254.

9. Jinkins JR: Atlas of Neuroradiologic Embryology, Anatomy, and Variants . Lippincott Williams \& Wilkins, Philadelphia; 2000.

10. Singh S, Singh SP: Atresia of the vertebral artery and its clinical significance . 1971, Neurol India; 19. 172-6

11. Nakashima H, Shigemori M, Kikuchi T, Tokutomi T, Kuramoto S: Pseudoaneurysm of the extracranial vertebral artery; a case report (in Japanese). No Shinkei Geka. 1991, 19:789-93. 
12. Burger IM, Siclari F, Gregg L, Gailloud P: Bilateral segmental agenesis of the vertebrobasilar junction: developmental and angiographic anatomy. AJNR Am J Neuroradiol. 2007, 28:201722.

13. Hoh BL, Rabinov JD, Pryor JC, Hirsch JA, Dooling EC, Ogilvy CS: Persistent nonfused segments of the basilar artery: longitudinal versus axial nonfusion. AJNR Am J Neuroradiol. 2004, 25:1194-6.

14. Weona YC, Chung JI, Kima HJ, Byuna HS: Agenesis of bilateral internal carotid arteries and posterior fossa abnormality in a patient with facial capillary hemangioma: Presumed incomplete phenotypic expression of PHACE syndrome. AJNR Am J Neuroradiol. 2005, 26:2635-2639.

15. Liebeskind D: Collateral circulation. Stroke. 2003, 34:2279-2284.

16. Castro S, Abreu P, Azevedo E, Silva ML: A new pattern of arterial rete compensation of segmental basilar agenesis associated with carotid retia mirabilia: a case report (2010: 1b). Eur Radiol. 2010, 20:1024-8. 10.1007/s00330-009-1491-6

17. Hyogo T, Nakagawara J, Nakamura J, Suematsu K: Multiple segmental agenesis of the cerebral arteries: case report. Neuroradiology. 1996, 38:433-6.

18. Perren F, Poglia D, Landis T, Sztajzel R: Vertebral artery hypoplasia: a predisposing factor for posterior circulation stroke?. Neurology. 2007, 68:65-7.

19. Olindo S, Khaddam S, Bocquet J, Chausson N, Aveillan M, Cabre P: Association between basilar artery hypoplasia and undetermined or lacunar posterior circulation ischemic stroke. Stroke. 2010, 41:2371-4. 10.1161/STROKEAHA.110.593145

20. Siddiqui AH, Chen PR: Intracranial collateral anastomoses: Relevance to endovascular procedures. Neurosurg Clin N Am. 2009, 20:279-96. 10.1016/j.nec.2009.04.013 